\title{
Laparoscopic low anterior resection for rectal cancer with rectal prolapse: a case report
}

\author{
Ryusei Yamamoto*, Yasuji Mokuno, Hideo Matsubara, Hirokazu Kaneko and Shinsuke lyomasa
}

\begin{abstract}
Background: Rectal cancer with rectal prolapse is rare, described by only a few case reports. Recently, laparoscopic surgery has become standard procedure for either rectal cancer or rectal prolapse. However, the use of laparoscopic low anterior resection for rectal cancer with rectal prolapse has not been reported.

Case presentation: A 63-year-old Japanese woman suffered from rectal prolapse, with a mass and rectal bleeding for 2 years. An examination revealed complete rectal prolapse and the presence of a soft tumor, $7 \mathrm{~cm}$ in diameter; the distance from the anal verge to the tumor was $5 \mathrm{~cm}$. Colonoscopy demonstrated a large villous tumor in the lower rectum, which was diagnosed as adenocarcinoma on biopsy. We performed laparoscopic low anterior resection using the prolapsing technique without rectopexy. The distal surgical margin was more than $1.5 \mathrm{~cm}$ from the tumor. There were no major perioperative complications. Twelve months after surgery, our patient is doing well with no evidence of recurrence of either the rectal prolapse or the cancer, and she has not suffered from either fecal incontinence or constipation.
\end{abstract}

Conclusions: Laparoscopic low anterior resection without rectopexy can be an appropriate surgical procedure for rectal cancer with rectal prolapse. The prolapsing technique is useful in selected patients.

Keywords: Rectal cancer, Rectal prolapse, Laparoscopic, Low anterior resection, Prolapsing technique

\section{Background}

Rectal prolapse is a pelvic disorder that typically occurs in older women with an incidence of $0.25 \%[1,2]$. Some reports state that laparoscopic surgery for transabdominal rectopexy is recommended because it is less invasive than open surgery [3, 4]. Laparoscopic low anterior resection (Lap-LAR) has been successfully adopted for rectal cancer because of its favorable short-term outcomes [5-9]. However, the coexistence of rectal cancer and rectal prolapse is extremely rare; thus, the etiology and treatment policy is still unclear. To the best of our knowledge, only three cases of rectal cancer with rectal prolapse (RCRP) have been reported [10-12], and none of these patients was treated with laparoscopic surgery. We present a patient with RCRP that was successfully resected using

\footnotetext{
* Correspondence: public.lock.on@gmail.com

Department of Surgery, Yachiyo Hospital, 2-2-7, Sumiyoshi-cho, Anjo-shi, Aichi 446-8510, Japan
}

(c) The Author(s). 2018 Open Access This article is distributed under the terms of the Creative Commons Attribution 4.0 International License (http://creativecommons.org/licenses/by/4.0/), which permits unrestricted use, distribution, and reproduction in any medium, provided you give appropriate credit to the original author(s) and the source, provide a link to the Creative Commons license, and indicate if changes were made. The Creative Commons Public Domain Dedication waiver (http://creativecommons.org/publicdomain/zero/1.0/) applies to the data made available in this article, unless otherwise stated.

\section{Case presentation}

A 63-year-old Japanese woman was referred to our hospital after suffering from rectal prolapse with a mass and rectal bleeding for 2 years. An examination revealed complete rectal prolapse of the entire thickness of the rectum with a soft, ulcerated tumor, $7 \mathrm{~cm}$ in diameter, included in the prolapse (Fig. 1). The tumor and prolapse were easily reduced manually; the distance from the anal verge to the tumor was $5 \mathrm{~cm}$. The anal sphincter tone was slightly diminished. The patient's laboratory data were normal except for anemia (hemoglobin level, $5.9 \mathrm{~g} / \mathrm{dL}$ ). Tumor markers were within normal limits: carcinoembryonic antigen was 2.8 and carbohydrate antigen $19-9$ was 6.2. A computed tomography scan revealed that the lower rectum was filled with a tumor measuring $7 \times 6 \mathrm{~cm}$, which was enhanced with contrast medium (Fig. 2). 

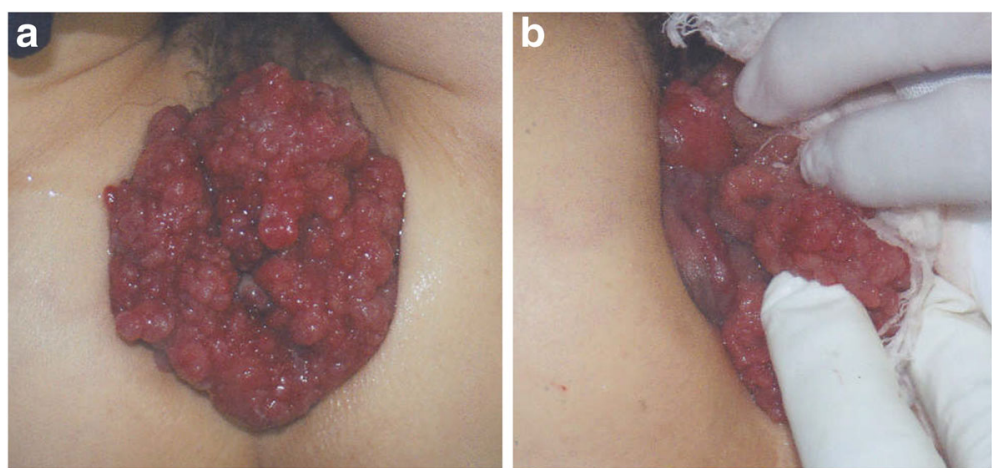

Fig. 1 Physical examination showing complete rectal prolapse of the entire thickness of the rectum with a soft, 7-cm tumor with ulceration. a frontal view, b: lateral view

There was no evidence of direct invasion of the tumor around the rectum, and no evidence of lymph node involvement or distant metastasis. A gastrografin enema revealed that the tumor was located in the posterior wall of the lower rectum (Fig. 3). Colonoscopy showed a large villous tumor in the lower rectum. The cauliflower shape of the tumor caused the edge to protrude laterally from its base, and the rim of the tumor appeared friable (Fig. 4). Biopsies of the tumor revealed adenocarcinoma. These findings suggested that the large, partially ulcerated tumor was not more than a T1 stage. We defined her cancer as clinical stage 1 ; cT1, cN0, cM0 according to the Union for International Cancer Control Classification of malignant tumors, $7^{\text {th }}$ edition. Therefore, we did not consider neoadjuvant chemoradiotherapy. Thus, we planned to perform Lap-LAR. To preserve the anal sphincter and to retract the part of the cauliflower-shaped tumor protruding over the wall of the rectum, ensuring a negative distal margin, we also planned to use a prolapsing technique.
Our patient was placed in the lithotomy position under general anesthesia, and five ports were inserted. We dissected the lymph nodes from the origin of the inferior mesenteric artery. We preserved the left colic artery and ligated and divided the superior rectal artery. The sigmoid colon and the rectum were mobilized using the total mesorectal excision technique, and the dissection was extended distally to expose the entire circumference of the levator ani muscle (Fig. 5). The proximal colon was transected using an endoscopic stapler. Then, we grasped the stump of the rectum using a forceps introduced anally and gently withdrew the stump under laparoscopic assistance. The distal rectum was easily everted and pulled outside of the anus (Fig. 6a). We transected the distal rectum $1.5 \mathrm{~cm}$ distal to the lower edge of the lesion under direct visualization, using the same stapler (Fig. 6b). An intraoperative frozen section revealed that the surgical margin was negative for tumor
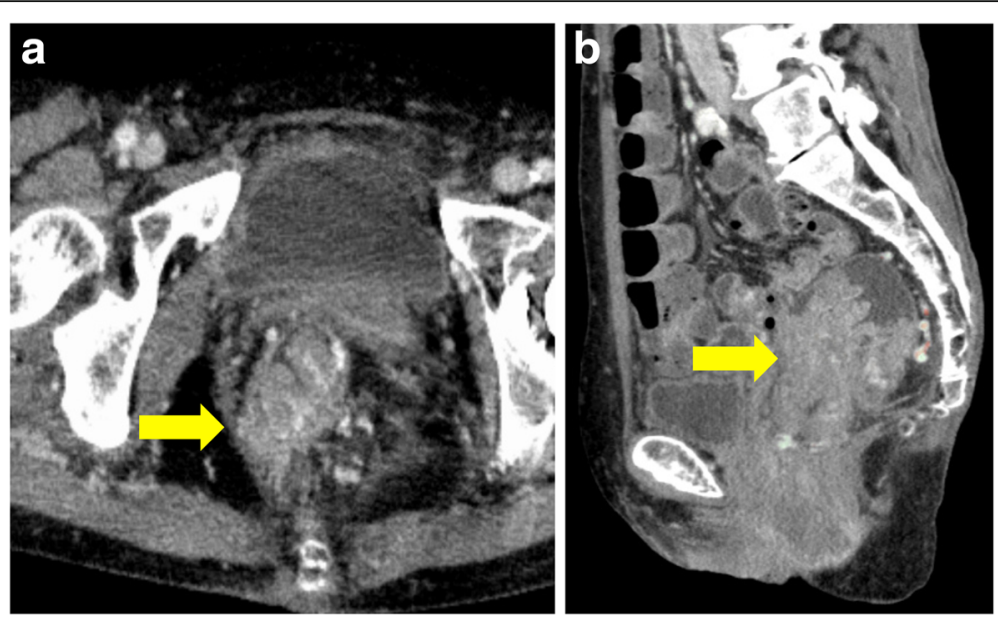

Fig. 2 Computed tomography scan showing the lower rectum filled with a tumor measuring $7 \times 6 \mathrm{~cm}$, enhanced with contrast medium. The arrows pointing to the tumor. $\mathbf{a}$ axial plane, $\mathbf{b}$ sagittal plane 

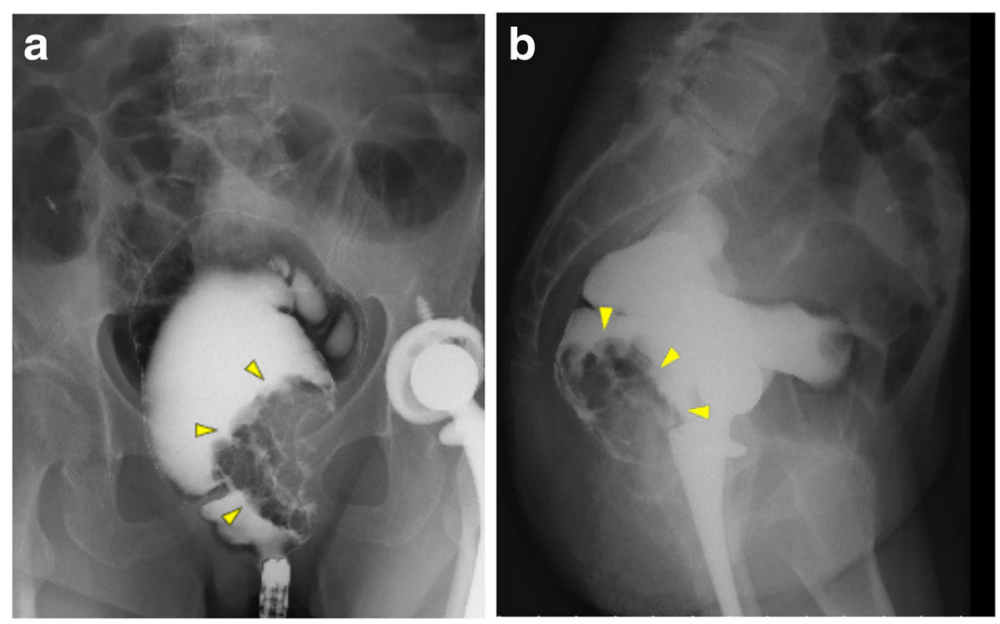

Fig. 3 Gastrografin enema showing a tumor located in the posterior wall of the lower rectum. The arrows pointing to the tumor. a coronal plane, b sagittal plane

involvement. We reduced the distal rectum, through the anus, back into the pelvis (Fig. 6). Then, we performed a minilaparotomy with a 4- $\mathrm{cm}$ incision at the umbilical port site to extract the proximal colon. We resected an extra $10 \mathrm{~cm}$ of proximal colon to create the proper length for an anastomosis and attached a 29-mm anvil head. We performed an end-to-end anastomosis using a double-stapling technique with a circular stapler. The operative time was 194 minutes, and the blood loss was $10 \mathrm{~mL}$.

On gross examination of the resected specimen, a cauliflower-shaped soft tumor with an ulcer was located in the lower rectum. The tumor measured $7 \times 8 \times 3 \mathrm{~cm}$, and the distal margin of the resected rectum was more than $1.5 \mathrm{~cm}$ from the tumor. Histological examination of the tumor showed moderately differentiated tubular

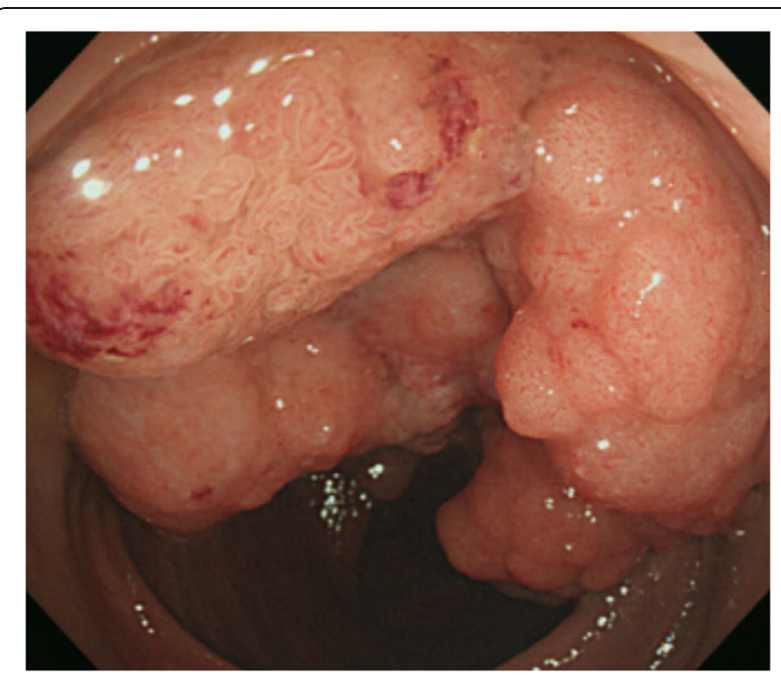

Fig. 4 Colonoscopy showing a large villous tumor in the lower rectum adenocarcinoma without regional lymph node metastasis. Almost the entire tumor was intramucosal, with focal invasion of the submucosal layer (stage 1; pT1, pN0, pM0) (Fig. 7). Our patient had an uneventful postoperative course. She had no fecal incontinence or constipation. Twelve months after surgery, she is doing well with no evidence of recurrence of either her rectal prolapse or her cancer.

\section{Discussion}

We elucidate here two important clinical issues: LapLAR without rectopexy can be an appropriate treatment for RCRP, and the prolapsing technique is useful for these patients.

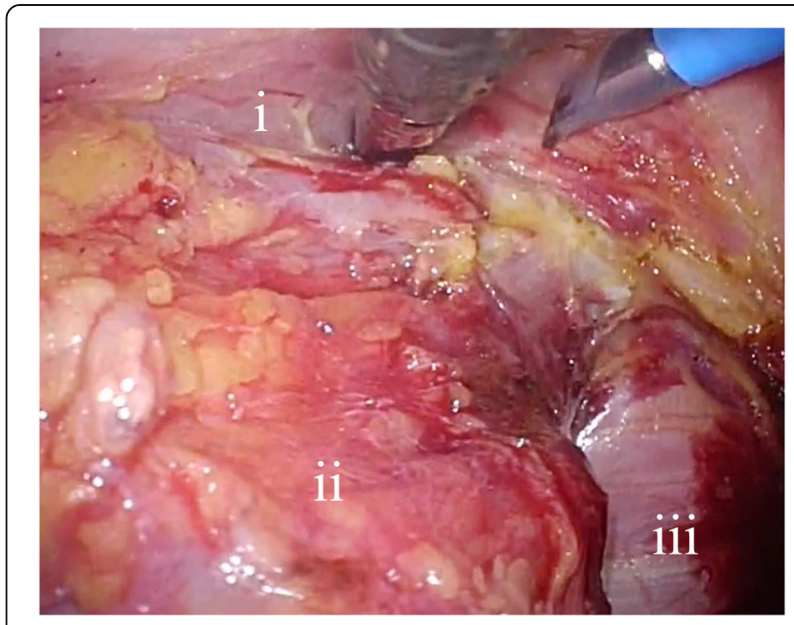

Fig. 5 Laparoscopic view showing mobilization of the rectum using the total mesorectal excision technique; the dissection is extended distally to expose the entire circumference of the levator ani muscle. i vagina; ii rectum; iii levator ani muscle 

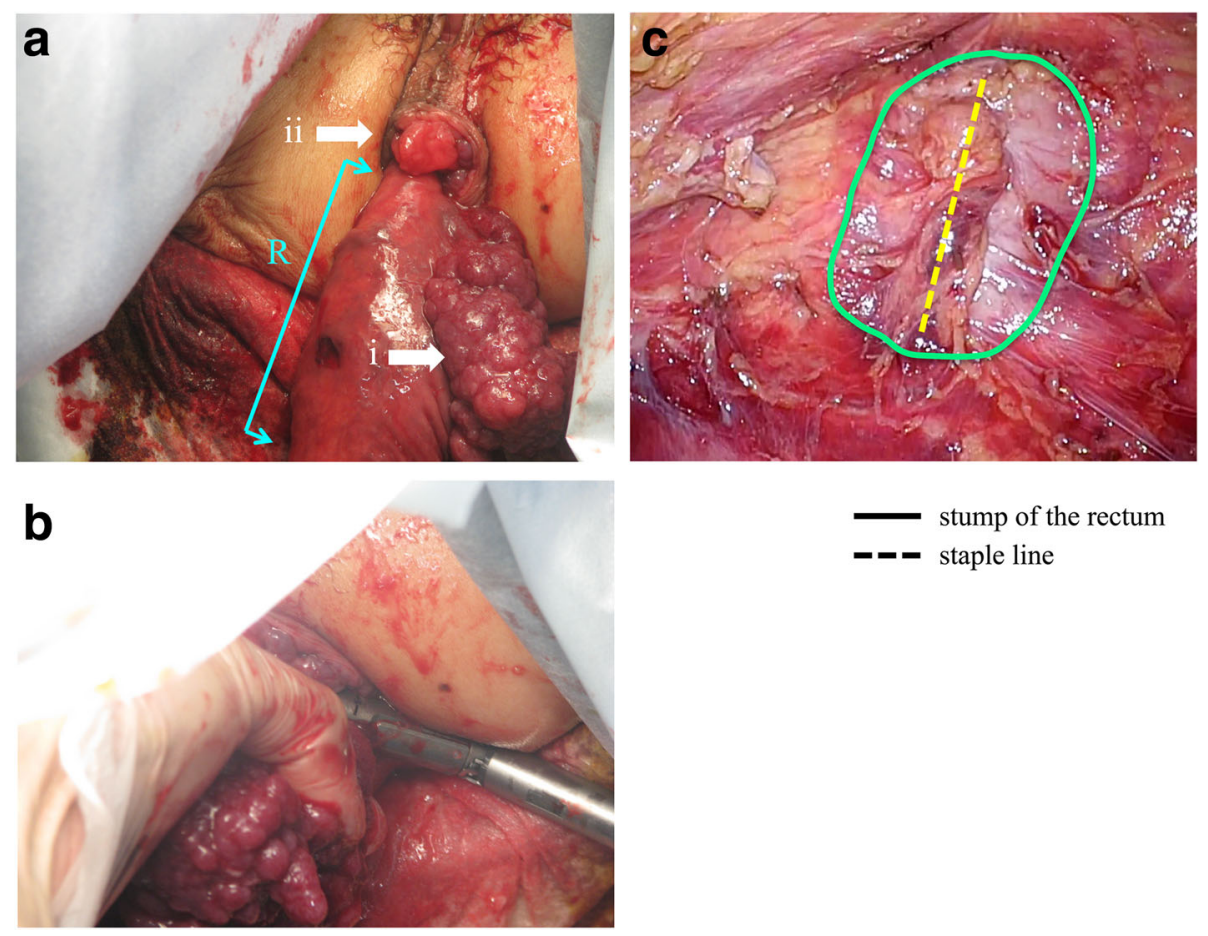

Fig. $\mathbf{6}$ a The distal rectum is everted and pulled outside of the anus. $i$ tumor; ii anus; $R$ everted rectum. $\mathbf{b}$ The distal rectum is transected under direct visualization. $\mathbf{c}$ Laparoscopic view showing the stump of the rectum reduced into the pelvis after resection
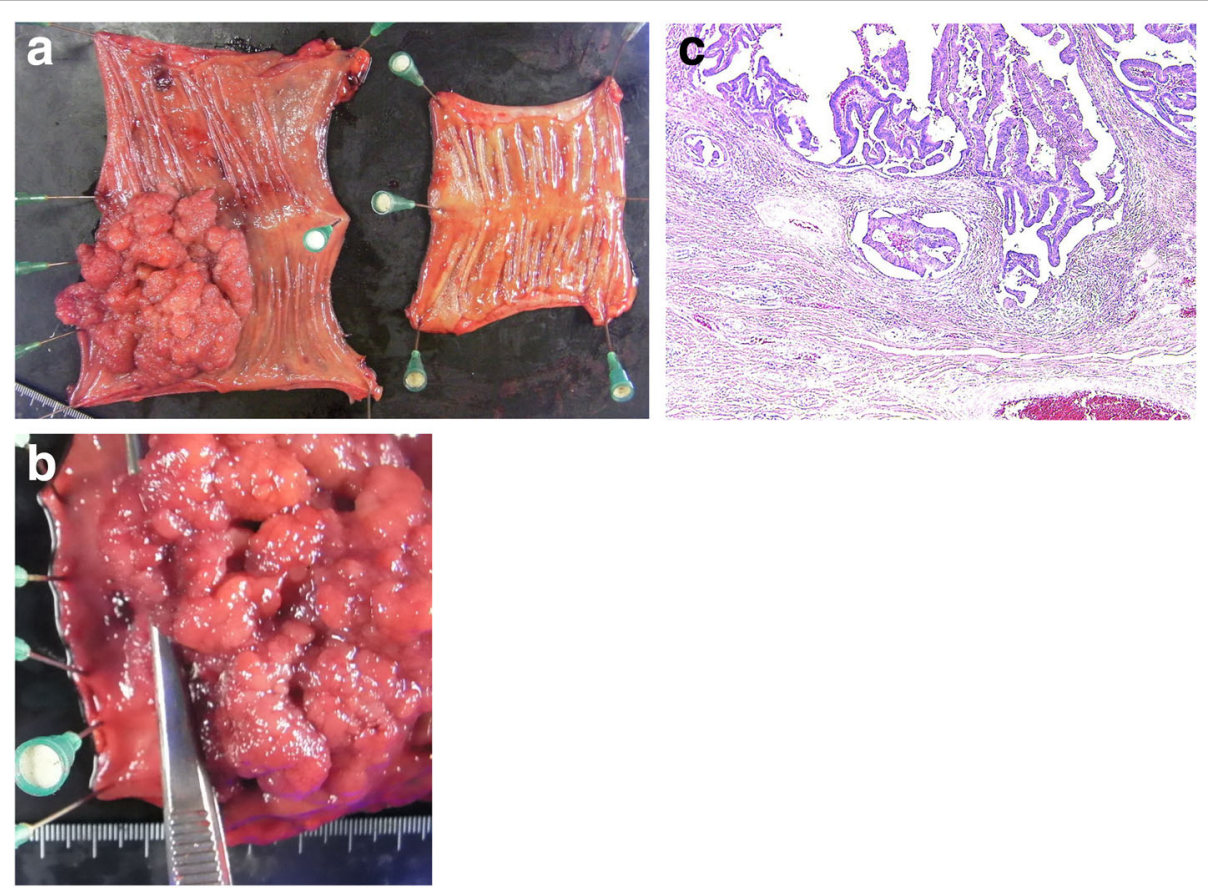

Fig. 7 a Gross examination showing an ulcerated, cauliflower-shaped, soft tumor, measuring $7 \times 8 \times 3 \mathrm{~cm}$, located in the lower rectum; the proximal colon is also resected. $\mathbf{b}$ The distal margin of the rectum is more than $1.5 \mathrm{~cm}$ from the tumor. $\mathbf{c}$ Histologic examination showing a moderately differentiated tubular adenocarcinoma, almost entirely intramucosal, with focal invasion of the submucosal layer 
Our review of the literature found five reports of colorectal cancer resection in patients with rectal prolapse; three of these patients had rectal cancer [10-14] (Table 1). However, only one patient was treated with low anterior resection; the others were treated using a perineal approach, and none was treated using laparoscopy. To the best of our knowledge, ours is the first report of RCRP treated with Lap-LAR. Because of the rarity of this condition, the etiology and treatment policy are still unclear. However, it is evident that priority should be placed on the oncological view, and we should follow the principles of surgical resection for rectal cancer. Laparoscopic surgery for rectal cancer has recently become the standard of care [5-9].

For rectal prolapse, there are two approaches to surgical repair: transabdominal and perineal. Many reports on the surgical treatment of rectal prolapse show that recurrence rates after abdominal repair are lower than after perineal repair [15-25]. Concomitant sigmoid resection is recommended for patients who have preexisting constipation [4, 26]. In a low anterior resection, a large part of the sigmoid colon is removed, and the reconstructed colon is straightened. After surgery, fibrosis of the dense area between the anastomotic line and the sacrum occurs, and the rectum is fixed to the sacrum; these changes act in a similar fashion to sigmoid resection and proctopexy $[15,27]$. Although our patient had a minimal distal margin of the rectum available for anastomosis, we determined that she was good candidate for sphincter preservation. We therefore performed Lap-LAR without rectopexy. At the time of writing this report, 12 months after surgery, our patient is doing well with no fecal incontinence or constipation. The outcome in our patient supports the use of this surgical procedure.

The prolapsing technique is useful for similar cases. In our patient, the tumor that filled the rectum was large and soft, and its cauliflower shape caused the friable edge to protrude laterally from its base, covering part of the rectal wall. These conditions posed two problems for conventional Lap-LAR: (1) although the distal margin of the rectum was minimally suitable for anastomosis, the dilated rectum hampered the laparoscopic view, compromising appropriate resection of the rectum; (2) the tumor rim would be included with the resected stump when the stapler made its cuts, possibly resulting in implantation of tumor cells. The prolapsing technique resolved these difficulties, enabling us to retract the tumor rim manually and to irrigate the rectum thoroughly. We were able to ensure the appropriate distal resection line, without including any part of the tumor with the cut edge of the rectum, under direct visualization. Intersphincteric resection of the rectum also may have enabled us to resect under direct visualization, but that technique is more invasive and increases the chance of seeding from the friable tumor. The use of Lap-LAR with the prolapsing technique is an established procedure, and our patient already had rectal prolapse, so the transanal eversion was easily accomplished [28, 29]. Our patient had good postoperative anal function and an adequate oncological resection margin. In our case, we did not create a temporary diverting stoma, because the anastomosis was performed without anxiety. However, Lap-LAR with the prolapsing technique sometimes requires a very low anastomosis, so a temporary diverting stoma should probably be used to protect an anastomosis. We speculate that the prolapsing technique not only satisfies the oncological view, but also preserves function and is a useful option for similar situations, such as a lower rectal cancer with a large, soft, friable tumor.

Etiologically, there is no apparent association between rectal cancer and rectal prolapse. Bowel intussusception in adults is typically due to a pathologic lead point (e.g., cancer, polyp) within the bowel that is pushed forward

Table 1 Patients with rectal prolapse and colorectal cancer

\begin{tabular}{|c|c|c|c|c|c|c|c|c|}
\hline Author & Years & Age (y) & Sex & $\begin{array}{l}\text { Location } \\
\text { of tumor }\end{array}$ & Pathology & Procedure & $\begin{array}{l}\text { Recurrence } \\
\text { of rectal } \\
\text { prolapse }\end{array}$ & $\begin{array}{l}\text { Recurrence } \\
\text { of cancer }\end{array}$ \\
\hline Yamazaki et al. [13] & 1999 & 76 & Female & $\begin{array}{l}\text { Sigmoid } \\
\text { colon }\end{array}$ & Carcinoma & $\begin{array}{l}\text { Sigmoidectomy + } \\
\text { Rectopexy }\end{array}$ & No & No \\
\hline Erikoğlu et al. [10] & 2004 & 63 & Female & Rectum & $\begin{array}{l}\text { Well diff. } \\
\text { adenocarcinoma }\end{array}$ & $\begin{array}{l}\text { Low anterior } \\
\text { resection }\end{array}$ & No & No \\
\hline Karmercan et al. [11] & 2007 & 33 & $\begin{array}{l}\text { Female } \\
\text { (pregnant) }\end{array}$ & Rectum & $\begin{array}{l}\text { Moderately diff. } \\
\text { adenocarcinoma }\end{array}$ & $\begin{array}{l}\text { Altemeier + } \\
\text { Proctocolectomy }\end{array}$ & No & No \\
\hline Bounovas et al. [14] & 2007 & 85 & Female & $\begin{array}{l}\text { Sigmoid } \\
\text { colon }\end{array}$ & Adenocarcinoma & $\begin{array}{l}\text { Sigmoidectomy + } \\
\text { Rectopexy }\end{array}$ & No & No \\
\hline Nabi [12] & 2015 & 77 & Female & $\begin{array}{l}\text { Rectum (After } \\
\text { Hartmann) }\end{array}$ & Adenocarcinoma & $\begin{array}{l}\text { Intersphincteric } \\
\text { perineal proctectomy }\end{array}$ & No & No \\
\hline
\end{tabular}


by normal peristalsis [30-32]. The same explanation may also fit rectal prolapse caused by rectal cancer. As mentioned above, there are three reported patients with RCRP, and all had relatively large tumors, with the rectum prolapsing and the tumor as a lead point. There are also case reports of large adenomas with rectal prolapse; in those patients, the tumor also functioned as a lead point $[33,34]$. On the other hand, a previous retrospective study reported that patients with rectal prolapse have an increased risk for colorectal cancer (5.7 versus 1.4 percent in the control group; relative risk, 4.18; 95\% confidence interval, 1.1-16.0) [35]. In any case, rectal prolapse is strongly related to colorectal cancer and we suggest that colorectal cancer should always be suspected when rectal prolapse is recognized.

\section{Conclusions}

In conclusion, we performed Lap-LAR using the prolapsing technique for a patient with RCRP. Our case suggests that Lap-LAR can be an appropriate surgical procedure for this presentation and that rectopexy is not always necessary. The prolapsing technique is useful in selected patients.

\section{Abbreviations}

Lap-LAR: Laparoscopic low anterior resection; RCRP: Rectal cancer with rectal prolapse

\section{Acknowledgements}

None.

\section{Funding}

None.

\section{Authors' contributions}

All authors contributed to the concept of this case report. RY drafted the manuscript, YM revised the manuscript, HM performed the surgery and postoperative management, and HK and SI supervised the writing of the report. All authors participated in interpreting the results and writing the report; all authors approved the final version of the manuscript.

\section{Ethics approval and consent to participate}

The institutional ethics committee approved the publication of this case report.

\section{Consent for publication}

Written informed consent was obtained from the patient for publication of this case report and any accompanying images. A copy of the written consent is available for review by the Editor-in-Chief of this journal.

\section{Competing interests}

The authors declare that they have no competing interests.

\section{Publisher's Note}

Springer Nature remains neutral with regard to jurisdictional claims in published maps and institutional affiliations.

Received: 9 May 2017 Accepted: 23 December 2017

Published online: 06 February 2018

\section{References}

1. Kairaluoma MV, Kellokumpu IH. Epidemiologic aspects of complete rectal prolapse. Scand J Surg. 2005;94:207-10.
2. Felt-Bersma RJ, Tiersma ES, Cuesta MA. Rectal prolapse, rectal intussusception, rectocele, solitary rectal ulcer syndrome, and enterocele. Gastroenterol Clin North Am. 2008;37:645-68. ix.

3. Henry LG, Cattey RP. Rectal prolapse. Surg Laparosc Endosc. 1994:4:357-60.

4. Purkayastha S, Tekkis P, Athanasiou T, Aziz O, Paraskevas P, Ziprin P, et al. A comparison of open vs. laparoscopic abdominal rectopexy for full-thickness rectal prolapse: a meta-analysis. Dis Colon Rectum. 2005;48:1930-40.

5. van der Pas MH, Haglind E, Cuesta MA, Fürst A, Lacy AM, Hop WC, Colorectal cancer Laparoscopic or Open Resection II (COLOR II) Study Group, et al. Laparoscopic versus open surgery for rectal cancer (COLOR II): short-term outcomes of a randomised, phase 3 trial. Lancet Oncol. 2013;14:210-8.

6. Jeong SY, Park JW, Nam BH, Kim S, Kang SB, Lim SB, et al. Open versus laparoscopic surgery for mid-rectal or low-rectal cancer after neoadjuvant chemoradiotherapy (COREAN trial): survival outcomes of an open-label, non-inferiority, randomised controlled trial. Lancet Oncol. 2014;15:767-74.

7. Arezzo A, Passera R, Salvai A, Arolfo S, Allaix ME, Schwarzer G, et al. Laparoscopy for rectal cancer is oncologically adequate: a systematic review and meta-analysis of the literature. Surg Endosc. 2015;29:334-48.

8. Kennedy RH, Francis EA, Wharton R, Blazeby JM, Quirke P, West NP, et al. Multicenter randomized controlled trial of conventional versus laparoscopic surgery for colorectal cancer within an enhanced recovery programme: EnROL. J Clin Oncol. 2014;32:1804-11.

9. Zhang FW, Zhou ZY, Wang HL, Zhang JX, Di BS, Huang WH, et al. Laparoscopic versus open surgery for rectal cancer: a systematic review and meta-analysis of randomized controlled trials. Asian Pac J Cancer Prev. 2014;15:9985-96.

10. Erikoğlu M, Tavli S, Tekin S. A rare case of rectal prolapse associated with rectal adenocarcinoma: case report. Turk J Gastroenterol. 2004;15:266-7.

11. Karamercan A, Tatlicioglu E, Ferahkose Z. Strangulation of a prolapsed rectal cancer in labor: a case report. J Reprod Med. 2007;52:545-7.

12. Nabi H. Rectal adenocarcinoma in prolapsed rectal stump following Hartmann's procedure. Int J Colorectal Dis. 2015;30:987-8.

13. Yamazaki T, Sakai Y, Sekine Y, Nihei K, Hatakeyama K. Sigmoid colon cancer presenting as complete rectal prolapse: report of a case. Surg Today. 1999; 29:266-7.

14. Bounovas A, Polychronidis A, Laftsidis P, Simopoulos C. Sigmoid colon cancer presenting as complete rectal prolapse. Colorectal Dis. 2007;9:665-6.

15. Madiba TE, Baig MK, Wexner SD. Surgical management of rectal prolapse. Arch Surg. 2005;140:63-73.

16. Portier G, lovino F, Lazorthes F. Surgery for rectal prolapse: Orr-Loygue ventral rectopexy with limited dissection prevents postoperativeinduced constipation without increasing recurrence. Dis Colon Rectum. 2006;49:1136-40.

17. Raftopoulos Y, Senagore AJ, Di Giuro G, Bergamaschi R, Rectal Prolapse Recurrence Study Group. Recurrence rates after abdominal surgery for complete rectal prolapse: a multicenter pooled analysis of 643 individual patient data. Dis Colon Rectum. 2005;48:1200-6.

18. Dulucq JL, Wintringer P, Mahajna A. Clinical and functional outcome of laparoscopic posterior rectopexy (Wells) for full-thickness rectal prolapse. A prospective study. Surg Endosc. 2007;21:2226-30.

19. Kim DS, Tsang CB, Wong WD, Lowry AC, Goldberg SM, Madoff RD. Complete rectal prolapse: evolution of management and results. Dis Colon Rectum. 1999;42:460-6. discussion 466-9.

20. Benoist S, Taffinder N, Gould S, Chang A, Darzi A. Functional results two years after laparoscopic rectopexy. Am J Surg. 2001;182:168-73.

21. Kariv Y, Delaney CP, Casillas S, Hammel J, Nocero J, Bast J, et al. Long-term outcome after laparoscopic and open surgery for rectal prolapse: a casecontrol study. Surg Endosc. 2006;20:35-42.

22. Lechaux D, Trebuchet G, Siproudhis L, Campion JP. Laparoscopic rectopexy for full-thickness rectal prolapse: a single-institution retrospective study evaluating surgical outcome. Surg Endosc. 2005;19:514-8.

23. Watts JD, Rothenberger DA, Buls JG, Goldberg SM, Nivatvongs S. The management of procidentia. 30 years' experience. Dis Colon Rectum. 1985; 28:96-102.

24. DiGiuro G, Ignjatovic D, Brogger J, Bergamaschi R, Rectal Prolapse Recurrence Study Group. How accurate are published recurrence rates after rectal prolapse surgery? A meta-analysis of individual patient data. Am J Surg. 2006;191:773-8.

25. Faucheron JL, Voirin D, Riboud R, Waroquet PA, Noel J. Laparoscopic anterior rectopexy to the promontory for full-thickness rectal prolapse in 175 consecutive patients: short- and long-term follow-up. Dis Colon Rectum. 2012;55:660-5. 
26. Tou S, Brown SR, Nelson RL. Surgery for complete (full-thickness) recta prolapse in adults. Cochrane Database Syst Rev. 2015(11):CD001758.

27. Kuijpers HC. Treatment of complete rectal prolapse: to narrow, to wrap, to suspend, to fix, to encircle, to plicate or to resect? World J Surg. 1992;16:826-30.

28. Fukunaga M, Kidokoro A, Iba T, Sugiyama K, Fukunaga T, Nagakari K, et al. Laparoscopy-assisted low anterior resection with a prolapsing technique for low rectal cancer. Surg Today. 2005;35:598-602.

29. Zhuo C, Liang L, Ying M, Li Q, Li D, Li Y, et al. Laparoscopic low anterior resection and eversion technique combined with a nondog ear anastomosis for mid- and distal rectal neoplasms: a preliminary and feasibility study. Medicine (Baltimore). 2015;94:e2285.

30. Newsom BD, Kukora JS. Congenital and acquired internal hernias: unusual causes of small bowel obstruction. Am J Surg. 1986;152:279-85.

31. Marinis A, Yiallourou A, Samanides L, Dafnios N, Anastasopoulos G, Vassiliou I, et al. Intussusception of the bowel in adults: a review. World J Gastroenterol. 2009;15:407-11.

32. Gayer G, Zissin R, Apter S, Papa M, Hertz M. Pictorial review: adult intussusception-a CT diagnosis. Br J Radiol. 2002;75:185-90.

33. Ongom PA, Lukande RL. Precipitous intussusception with anal protrusion and complete overt rectal prolapse presenting with intestinal obstruction and an associated rectal adenoma in a young man: a case report. BMC Res Notes. 2013:6:401.

34. Mahmood A, Ruan QZ, O'Hara R, Canna K. Adult intussusception presenting as rectal prolapse. BMJ Case Rep. 2014. doi:https://doi.org/10.1136/bcr-2013203281

35. Rashid Z, Basson MD. Association of rectal prolapse with colorectal cancer. Surgery. 1996;119:51-5.

\section{Submit your next manuscript to BioMed Central and we will help you at every step:}

- We accept pre-submission inquiries

- Our selector tool helps you to find the most relevant journal

- We provide round the clock customer support

- Convenient online submission

- Thorough peer review

- Inclusion in PubMed and all major indexing services

- Maximum visibility for your research

Submit your manuscript at www.biomedcentral.com/submit 